\title{
ORIGINAL ARTICLE \\ Acute abdominal emergencies and spinal cord injury; our experiences: a retrospective clinical study
}

\author{
B Sarıfakıoğlu ${ }^{1}$, SI Afşar ${ }^{2}$, ŞA Yalbuzdağ ${ }^{3}$, K Ustaömer ${ }^{4}$ and Ş Ayaş ${ }^{2}$
}

Study design: Retrospective review of medical notes.

Objective: To describe clinical, laboratory and examination findings of acute abdominal emergencies (AAE) in Turkish patients with spinal cord injury (SCI) and to examine diagnosis and management of AAE in early stages.

Setting: Inpatient rehabilitation unit of tertiary research hospital.

Methods: The medical records of $237 \mathrm{SCl}$ patients were reviewed. The SCl patients who were recruited in the study had been diagnosed with $A A E$ and treated medically or surgically while they were inpatients at the rehabilitation clinic.

Results: Nine out of $237 \mathrm{SCl}$ patients had been diagnosed with one of the AAE. Three patients were AIS A, three patients were AIS B and three patients were AIS C. The most common AAE was acute cholecystitis; three patients were diagnosed with this. The others were single cases of intra-abdominal hemorrhage, intra-abdominal abscess, tuba-ovarian abscess, subileus, Crohn's disease and cholangitis. Three of the patients were treated with surgery and six were treated medically. The most common symptoms in patients were fever, abdominal pain and abdominal discomfort (four of AAE). Three patients had abdominal tenderness and abdominal distension. The expected findings of AAE, rebound and defense, were positive only in two patients.

Conclusion: Gall bladder disease is a common cause of AAE. The classic symptoms and examination findings will usually not facilitate acute abdomen diagnosis in the SCI group, so we should be aware of patients' subjective complaints and when necessary use advanced imaging techniques immediately.

Spinal Cord (2014) 52, 697-700; doi:10.1038/sc.2014.106; published online 8 July 2014

\section{INTRODUCTION}

Spinal cord injury (SCI) is an acute neurological condition causing devastating loss of function and poor short- and long-term prognosis. With advances in emergency medical services and improved trauma care, mortality continues to decrease especially in the acute phase of SCI. ${ }^{1,2}$ Unfortunately, as more patients survive, a greater number now face long-term complications such as urinary tract infections, pneumonia and pressure ulcers. ${ }^{3}$

Gastrointestinal problems are common in SCI patients. ${ }^{4}$ Acute abdominal emergency (AAE) diagnosis can be very difficult among this group of patients. Classic signs may be different, mild nonexistent or difficult to observe. ${ }^{5}$ For these reasons, diagnosis may be delayed and mortality may be increased. Approximately, 10\% of SCI patients die of acute abdominal problems. ${ }^{6}$

The aim of this study is to describe clinical, laboratory andphysical findings of AAE in Turkish patients with SCI, and to examine diagnosis and management of AAE in early stages.

\section{MATERIALS AND METHODS}

This study was conducted with the approval of the ethics committee of Baskent University (KA12/265).

The medical records of 237 SCI patients admitted to Baskent University Ayas Physical Medicine and Rehabilitation Center from January 2007 to
October 2012 were reviewed. The SCI patients who were recruited in the study had been diagnosed with AAE and treated medically or surgically while they were inpatients at the rehabilitation clinic. Patients included had SCIs above $\mathrm{T} 12$ and clinical and/or laboratory diagnoses of acute abdominal conditions. SCI patients with a neurological injury below T12 (because the somatic innervation of the abdominal wall may be intact), pediatric patients and patients with impaired cognitive function were excluded from the study.

The patients' demographic findings, the American Spinal Injury Association (ASIA) impairment scale (AIS) grade and neurological levels, SCI etiology and time since injury were recorded. Patients' clinical, examination, laboratory and radiological findings were also recorded, as well as their last AAE diagnosis and treatments.

\section{RESULTS}

We screened 237 SCI patients, of whom nine had been diagnosed with AAE conditions during their inpatient rehabilitation program.

Six of these patients were female and three were male. The mean age was $50 \pm 15$ years (median 50, range 24-71). The etiology of lesion was traumatic in seven patients and non-traumatic in two patients. Three patients were AIS A, three were AIS B and three were AIS C. Five patients' neurological levels were above T8 and four were below T8. Time between SCI and AAE ranged from 1-150 months (mean was $23 \pm 49$, median was 23 months). Demographic and clinical characteristic of the patients are presented in Table 1 .

${ }^{1}$ Department of Physical Medicine and Rehabilitation, School of Medicine, Namik Kemal University, Tekirdağ, Turkey; ${ }^{2}$ Department of Physical Medicine and Rehabilitation, School of Medicine, Baskent University, Ankara, Turkey; ${ }^{3}$ Department of Physical Medicine and Rehabilitation, Bozyaka Research and Training Hospital, İzmir, Turkey and ${ }^{4}$ Department of Physical Medicine and Rehabilitation, Özel Optimed Hospital, Tekirdağ, Turkey

Correspondence: Dr B Sarıfakıoglu, Department of Physical Medicine and Rehabilitation, School of Medicine, Namik Kemal University, 100 Yil Mah. Barbaros Cad. Merkez, Tekirdag 59030, Turkey.

E-mail: banusarifakioglu@yahoo.com

Received 27 December 2013; revised 20 May 2014; accepted 28 May 2014; published online 8 July 2014 
The most common AAE was acute cholecystitis; three patients were diagnosed with this. The others were single cases of intra-abdominal hemorrhage, intra-abdominal abscess, tuba-ovarian abscess, subileus, Crohn's disease (CD) and cholangitis. The most common symptoms in patients were fever, abdominal pain and abdominal discomfort (four of AAE). Abdominal pain was usually not localized. Two patients had vomiting; and only one patient had constipation.

Table 1 Demographic and clinical characteristic of the patients

\begin{tabular}{lcclccc}
\hline Patient & $\begin{array}{c}\text { Age } \\
\text { (years) }\end{array}$ & Sex & Etiology & $\begin{array}{c}\text { Als } \\
\text { (grade) }\end{array}$ & $\begin{array}{r}\text { Level of } \\
\text { injury }\end{array}$ & $\begin{array}{c}\text { Time post } \\
\text { injury (months) }\end{array}$ \\
\hline 1 & 24 & F & MVA & C & T10 & 2 \\
2 & 38 & M & MVA & A & C5 & 2 \\
3 & 71 & F & Fall & C & T12 & 40 \\
4 & 55 & M & Operated CDH & B & C3 & 150 \\
5 & 50 & F & MVA & A & C5 & 2 \\
6 & 56 & F & Fall & A & T10 & 1 \\
7 & 34 & F & MVA & B & C6 & 6 \\
8 & 67 & M & MVA & B & C6 & 1 \\
9 & 53 & F & TM & C & T12 & 2 \\
\hline
\end{tabular}

Abbreviations: AIS, American spinal Injury Association Impairment Scale; $\mathrm{CDH}$, cervical disc herniation; F, female; M, male; MVA, motor vehicle accident; TM, transvers myelitis.
Otherwise, physical examination was non-specific and laboratory findings were also unremarkable. Radiographic studies, especially ultrasonography (US) and computerized tomography (CT), were able to produce the correct diagnoses. Only one patient underwent US twice; the first results were normal, but the second detected left tubaovarian abscess. One patient underwent abdominal CT after US in order to double check the diagnosis. One patient's diagnosis was confirmed using rectosigmoidoscopy.

Patient number 5 was initially diagnosed with deep vein thrombosis (DVT) and pulmonary embolism based on her clinical and examination findings. Thoracic CT, was performed and the results were normal; her fever and clinical complaints continued but her urine examination results were normal, and there was no reason for the fever to persist. Then abdominal CT was performed for the etiology of the persistent fever, and perforated cholecystitis was detected.

Patients' clinical, laboratory and examination findings, diagnoses and therapies were summarized in Table 2.

\section{DISCUSSION}

One of the most common complications following SCI is gastroenterological complications (1.9-11\%), including gastroparesis, peptic ulcer, constipation and colitis. ${ }^{7-9}$ These can mimic the signs and symptoms of AAE. ${ }^{5}$ The incidence of AAE in SCI is believed to be

Table 2 Characteristics of the patients with acute abdomen emergencies

\begin{tabular}{|c|c|c|c|c|c|c|}
\hline Patient & Diagnosis & Clinical symptoms & Examination findings & Laboratory findings & Radiologic findings & Therapies \\
\hline 1 & Pelvic hematoma & $\begin{array}{l}\text { Abdominal pain, vomit- } \\
\text { ing, lack of appetite, } \\
\text { weakness }\end{array}$ & $\begin{array}{l}\text { Abdominal distension, } \\
\text { diffuse tenderness, } \\
\text { defense, rebound }\end{array}$ & $\begin{array}{l}\text { Hemoglobin: } 6 \mathrm{mgdl}^{-1} \text {, } \\
\text { hematuria, INR:10.91 }\end{array}$ & $\begin{array}{l}\text { USG: intra-abdominal } \\
\text { bleeding and pelvic } \\
\text { hematoma }\end{array}$ & $\begin{array}{l}\text { Medical treatment } \\
\text { (replace of erythrocyte } \\
\text { suspension, fresh-fro- } \\
\text { zen plasma) }\end{array}$ \\
\hline 2 & Cholangitis & $\begin{array}{l}\text { Abdominal discomfort, } \\
\text { vomiting }\end{array}$ & $\begin{array}{l}\text { Hyperactive bowel } \\
\text { sounds }\end{array}$ & $\begin{array}{l}\text { Mild transaminase } \\
\text { elevation }\end{array}$ & $\begin{array}{l}\text { USG: gall bladder } \\
\text { thickening CT: Acute } \\
\text { cholangitis }\end{array}$ & $\begin{array}{l}\text { Medical treatment } \\
\text { (ERCP could not be } \\
\text { made because of cervi- } \\
\text { cal implant) }\end{array}$ \\
\hline 3 & Acute cholecystitis & $\begin{array}{l}\text { Fever }\left(39^{\circ} \mathrm{C} \text {, abdominal }\right. \\
\text { pain) }\end{array}$ & $\begin{array}{l}\text { Diffuse tenderness, } \\
\text { defense }\end{array}$ & $\begin{array}{l}\text { Mild transaminase ele- } \\
\text { vation, leukocytosis: } \\
15600 \text { per } \mu \text { l }\end{array}$ & CT: acute cholecystitis & $\begin{array}{l}\text { Surgical treatment } \\
\text { (cholecystectomy) }\end{array}$ \\
\hline 4 & Acute cholecystitis & $\begin{array}{l}\text { Persistent fever } \\
\left(38.5^{\circ} \mathrm{C}\right) \text {, malaise }\end{array}$ & Normal & $\begin{array}{l}\text { Leukocytosis: } 12700 \\
\text { per } \mu \text { l, ESR: } 80 \mathrm{~mm} \mathrm{~h}^{-1}\end{array}$ & USG: cholelitiazis & $\begin{array}{l}\text { Surgical treatment } \\
\text { (cholecystectomy) }\end{array}$ \\
\hline 5 & $\begin{array}{l}\text { Perforated acute } \\
\text { cholecystitis }\end{array}$ & Fever $\left(38^{\circ} \mathrm{C}\right)$ & $\begin{array}{l}\text { Widespread rhonchi, } \\
\text { basal crackles }\end{array}$ & $\begin{array}{l}\text { Leukocytosis } 13700 \\
\text { per } \mu \mathrm{l} \text {, } \\
\text { D-dimer:3.64 } \mathrm{ng} \mathrm{ml}^{-1}\end{array}$ & $\begin{array}{l}\text { Thorax CT: normal } \\
\text { Abdominal CT: perfo- } \\
\text { rated acute } \\
\text { cholecystitis }\end{array}$ & $\begin{array}{l}\text { Surgical treatment } \\
\text { (cholecystectomy) }\end{array}$ \\
\hline 6 & $\begin{array}{l}\text { Intra-abdominal } \\
\text { abscess }\end{array}$ & Abdominal discomfort & $\begin{array}{l}\text { Hypoactive bowel } \\
\text { sounds }\end{array}$ & $\begin{array}{l}\text { Mild elevated } \\
\text { transaminase }\end{array}$ & $\begin{array}{l}\text { CT: intra-abdominal } \\
\text { abscess }\end{array}$ & $\begin{array}{l}\text { Medical (IV antibiotics, } \\
\text { nasal tube } \\
\text { decompression) }\end{array}$ \\
\hline 7 & $\begin{array}{l}\text { Left tuba-ovarian } \\
\text { abscess }\end{array}$ & $\begin{array}{l}\text { Lower quadrant pain, } \\
\text { groin tension, abdom- } \\
\text { inal discomfort }\end{array}$ & Normal & $\begin{array}{l}\text { Normal leukocytes, } \\
\text { ESR, CRP and } \\
\text { transaminases }\end{array}$ & $\begin{array}{l}\text { USG: left tuba-ovarian } \\
\text { abscess }\end{array}$ & $\begin{array}{l}\text { Medical (patient did not } \\
\text { accept the surgery, IV } \\
\text { antibiotics) }\end{array}$ \\
\hline 8 & Subileus & $\begin{array}{l}\text { No gas and stool output } \\
\text { for } 5 \text { days, abdominal } \\
\text { pain, distcomfort and } \\
\text { fever }\left(37.5^{\circ} \mathrm{C}\right)\end{array}$ & $\begin{array}{l}\text { Abdominal distension, } \\
\text { hyperactive bowel } \\
\text { sounds, mild abdominal } \\
\text { tenderness }\end{array}$ & $\begin{array}{l}\text { Normal leukocytes, } \\
\text { ESR, CRP and } \\
\text { transaminases }\end{array}$ & - & $\begin{array}{l}\text { Medical treatment } \\
\text { (stopped oral feeding, } \\
\text { rectal tube) }\end{array}$ \\
\hline 9 & Crohn's disease & $\begin{array}{l}\text { Abdominal pain, fever } \\
\left(38^{\circ} \mathrm{C}\right) \text {, diarrhea }\end{array}$ & Normal & CRP: $91 \mathrm{mgl}^{-1}$ & $\begin{array}{l}\text { CT: colitis in the sig- } \\
\text { moid colon rectosig- } \\
\text { moidoscopy: Crohn's } \\
\text { disease }\end{array}$ & $\begin{array}{l}\text { Medical therapy (pre- } \\
\text { dnisolone } 32 \mathrm{mg} \text { per } \\
\text { daily oral tablet, Asacol) }\end{array}$ \\
\hline
\end{tabular}


almost same with the general population, ${ }^{10}$ and it is important to diagnose this as early as possible because of its high mortality rate. ${ }^{10,11}$ Advanced age, male gender, cervical spinal cord lesions and other traumas may increase the mortality rate. ${ }^{9}$ This study found 9 AAE of 237 SCI patients. This result corresponds with the literature: Miller et al. ${ }^{10}$ found 21 cases spanning 16 years (total SCI patient count was not given), Neumayer et al. ${ }^{12}$ found 21 patients (one case had two different episodes) spanning 10 years in 145 SCI patients, and Bar-On et al. ${ }^{13}$ found 12 patients spanning 14 years in $1300 \mathrm{SCI}$ patients.

Diagnosing AAE can be difficult. Neurological impairment usually masks the classic symptoms and findings. In one study, abdominal pain was the most common complaint (four patients of $21 \mathrm{SCI}$ patients fairly well localized, five patients poorly localized). ${ }^{10}$ Commonly observed symptoms include malaise, nausea and a feeling of something wrong. ${ }^{12,13}$ Fever (32\%), distension (27\%), tenderness with palpation (50\%), hypoactive bowel sounds (18\%), rigidity (14\%) and leukocyturia (55\%) are the most common findings in laboratory and physical examination. ${ }^{10,12,14}$ According to our study, fever, abdominal discomfort and abdominal pain were the most frequently observed symptoms, while tenderness, distension, leukocytosis were the most common findings. In a recent study, researchers have found that the most common and early finding of AAE was anorexia, but in our study only one patient had anorexia. ${ }^{11}$

Persistent fever and associated abdominal discomfort may be the only findings of AAE. Fever and presence of leukocyturia in urine are often considered as the symptoms of urinary tract infections, and therefore need to be treated. One must consider that these findings may suggest acute abdomen. Autonomic dysreflexia is one of the most common symptoms of acute abdomen. ${ }^{11}$ In our patient series, only one patient had autonomic dysreflexia; this may be because most of our AAE patients were sensory intact. It should nevertheless be remembered that autonomic dysreflexia might be earliest symptom of AAE.

Gall bladder disease was the most common acute abdomen in our case series (four patients, one of them was cholangitis, three were acute cholecystitis). Surveys have shown gallstone prevelance of $25-49 \%$ in the SCI population, $10-15 \%$ in normal populations and $7 \%$ in our country. ${ }^{15-17}$ All these findings support that SCI is a risk factor for developing cholelithiasis. ${ }^{16,18}$ The reason for the increase in gallstone formation in this group of patients is not clear, ${ }^{19}$ but it may be related to altered metabolic state and impaired gall bladder relaxation in an SCI patient with injury at T10 or above. ${ }^{20}$ The studies showed normal gall bladder contraction and secretion of the cholecystokinin in SCI group, but gall bladder relaxation may impair at the T10 and higher levels.,20,21 One study showed that gall bladder fasting volume and ejection fraction were significantly less in SCI above T10. ${ }^{20}$ This may be about that the gall bladder is innervated from T7-T10 segments of the spinal cord. Also in the same study, they have found increased of biliary sludge above T10 SCI patients. ${ }^{20}$ Nino-Murcina et $a l .{ }^{4}$ found that lower resting volume in SCI patients $(21 \mathrm{ml})$ compared with healthy subjects $(28 \mathrm{ml})$, and they suggested that lower resting volume may be making patients' bile more lithogenic. Our two cholecystitis and one cholangitis patients had SCIs above T10, of which one was at T12. All our patients with cholecystitis gall baldder disease had different findings. This may be related to the difference in their neurological state (two paraplegic and two quadriplegic patients) and sensory state (two AIS A, one AIS B and one AIS C patient). Fever is the most common finding in cholecystitis patients in the general population, and all our cholecystitis patients presented with this. Fever may be ascribed to a concurrent condition such as urinary tract infection in SCI patients.

Xia and et al. ${ }^{22}$ found acute cholecystitis in $26 \%$ of 100 SCI patients and $10 \%$ of the control group. All their patients were male and the time since injury was over 1 year. Similarly, Rotter et al. ${ }^{16}$ have studied 100 male SCI patients and found cholelithiasis in $25 \%$ of the AIS A-B, and $25 \%$ of the AIS C-D groups. Apstein found acute cholecystitis in $29 \%$ of SCI patients at autopsy. ${ }^{18}$ Ryu et al. ${ }^{23}$ found 134 cases of acute calculous cholecystitis in 134 patients (79 males, 55 females) who had undergone cholecystectomy. Moonka et al. ${ }^{19}$ found increasing age and female gender to be risk factors for gallstone formation. We did not find any gender difference when we evaluate all gall bladder diseases (acute cholecystitis and cholangitis) in our study (two males, two females). Studies have generally been conducted on the male population or found more male patients than females. A possible reason is that SCI is more common in males.

Two of our patients were in the early stage ( $<6$ months) and two in the late stage ( $>6$ months) of SCI. Other studies have not found any relationship between the time since injury and the presence of gall bladder disease. ${ }^{16,18,22}$ Formation of sludge in the gall bladder has been shown in the early phase of injury (in the first 6 months) at a rate of $19 \%$. Autonomic nervous system dysfunction in SCI patients is seen especially within 6 months of the trauma, after which the autonomic nervous system recovers and shows normal function. ${ }^{24}$ Sludge formation is therefore higher in the early stages following trauma. Cholangitis was seen at the second month of SCI in our case number 2 and may be related to autonomic nervous system dysfunction. Our two patients with AAE in 2 months had a high level of injury (both of them were C5 AIS A). Studies have shown that high level injuries increase the risk of gall bladder disease ${ }^{22,25}$ and this could explain our patient's status.

We found two abscesses, one retroperitoneal and the other tubaovarian); the two patients had no fever, abdominal defense or rebound. The patient with tuba-ovarian abscess was experiencing left lower quadrant pain because she had intact sensation (AIS B). The other patient had only abdominal distension, mild elevated transaminase levels and hypoactive bowel sounds. SCI patients usually have abdominal distension and hypoactive bowel sounds, ${ }^{11}$ so these findings may be considered unhelpful. Patients with SCI can be immune compromised due to factors including altered metabolic status, malnutrition, prolonged bed rest, catheter usage. Infection and associated abscess risk may therefore be increased. Also, repeated interventional procedures such as intermittent catheterization may increase infection and abscess risk, especially in women, because they have short urethra.

In our study, we have encountered a single case of intra-abdominal bleeding and hematoma. In last years, gastrointestinal bleeding ratio decreased from $3.2-1.0 \% .^{26}$ In SCI, anti-platelet and low-molecularweight heparin are usually used in order to avoid DVT and pulmonary embolism. Our patient did not receive prophylactic therapy for DVT, and after she presented with DVT in the acute care center she was administered with warfarin $5 \mathrm{mg}$ p.o. daily, acetylsalicylic acid $300 \mathrm{mg}$ p.o. daily and low-molecular-weight heparin $0.6 \mathrm{ml}$ per IM twice a day. On admission to our center, she showed signs of acute abdomen (abdominal pain, vomiting and lack of appetite) and of bleeding (weakness, paleness, tachycardia and hypotension). US was performed immediately and intra-abdominal bleeding detected, so the patient was treated with erythrocyte suspension and fresh-frozen plasma before she was decompensated.

$\mathrm{CD}$ is characterized by involvement of the gastrointestinal canal with abdominal pain, diarrhea, fever and weight loss. ${ }^{26}$ Three of these findings were observed in our patient with CD. Fever and abdominal 
pain were seen in the other AAE; in this case, persistent diarrhea lead to diagnosis of the pathology. In the literature, only two patients have so far been diagnosed with CD following SCI. ${ }^{10,26}$ To the best of our knowledge, our patient is the third. If a patient has no history of CD but displays the appropriate symptoms and persistent diarrhea, diagnosis of CD should be considered.

We have found only one subileus. This is a common problem in cases of spinal shock. ${ }^{7}$ Our patient had some classic clinical findings (lack of output of gas and stool, abdominal distension, mild abdominal tenderness and abdominal pain), but he had no nausea or vomiting. The patient's bowel sounds increased at first, but then disappeared at the follow-up. This finding is similar to that of Juler et al. ${ }^{11}$; nevertheless, monitoring bowel sounds is useful in these cases.

In our case series, none of the patients died due to acute abdomen. This may be due to the rehabilitation team's experience and the use of radiological examination techniques in the early stages of the diseases. The most common cause of death was reported as perforated viscus with peritonitis. ${ }^{10}$ In our case series, there was only one patient with perforated cholecystitis, and the others were diagnosed in the early stages. This study showed that radiological examination is crucial in diagnosing the pathology, and if radiological examination was normal but patient complaints continue, then specific radiological examination should be repeated. In one case, first abdominal US was normal but tuba-ovarian abscess was detected in a second US. Due to the technical difficulties involved (positioning, increased gas), initial US examinations may not indicate pathology, and if clinical suspicion continues, then abdominal CT should be implemented immediately or a second US should be scheduled.

The study has some limitations including a small cohort size, a relatively short follow-up period and retrospective study design.

In conclusion, the classic symptoms and examination findings will usually not facilitate acute abdomen diagnosis in the SCI group, so we should be aware of patients' subjective complaints and when necessary use advanced imaging techniques immediately. AAE could be mortal in the healthy group, and due to difficulties in diagnosis in the SCI group, it is considered much more significant.

\section{DATA ARCHIVING}

There were no data to deposit.

\section{CONFLICT OF INTEREST}

The authors declare no conflict of interest.
1 Johnson RL, Grehart KA, McCray J, Menconi JC, Whiteneck CG. Secondary conditions following spinal cord injury in a population-based sample. Spinal Cord 1998; 36 $35-50$.

2 Selvarajah S, Hammond ER, Haider AH, Abularrage CJ, Becker D, Dhiman N et al. The burden of acute traumatic spinal cord injury among adults in the united states: an update. J Neurotrauma 2014; 1: 228-238.

3 Chiodo AE, Scelza WM, Kirshblum SC, Wuermser LA, Ho CH, Priebe MM. Spinal cord injury medicine. 5. Long-term medical issues and health maintenance. Arch Phys Med Rehabil 2007; 88: 76-83.

4 Nino-Murcia M, Burton D, Chang P, Stone J, Perkash I. Gallbladder contractility in patients with spinal cord injuries: a sonographic investigation. AJR Am J Roentgenol 1990; 154: 521-524.

5 Mowrey K. The challenge of assessing and diagnosing acute abdomen in tetraplegics: A case study. J Neurosci Nurs 2007; 39: 5-8.

6 Berlly $\mathrm{MH}$, Wilmot $\mathrm{CB}$. Acute abdominal emergencies during the first four weeks after spinal cord injury. Arch Phys Med Rehabil 1984; 65: 687-690.

7 Ebert E. Gastrointestinal involvement in spinal cord injury: a clinical perspective. J Gastrointestin Liver Dis 2012; 21: 75-82.

8 Gore RM, Mintzer RA, Calenoff L. Gastrointestinal complications of spinal cord injury. Spine 1981; 6: 538-544

9 Matsumura JS, Prystowsky JB, Bresticker MA, Meyer PR Jr, Joehl RJ, Nahrwold DL. Gastrointestinal tract complications after acute spine injury. Arch Surg 1995; 130 751-753.

10 Miller BJ, Geraghty TJ, Wong CH, Hall DF, Cohen JR. Outcome of the acute abdomen in patients with previous spinal cord injury. ANZ J Surg 2001; 71: 407-411.

11 Juler LG., Eltorai MI. The acute abdomen in spinal cord injury patients. Paraplegia 1985; 23: 118-123.

12 Neumayer LA, Bull DA, Mohr JD, Putnam CW. The acutely affected abdomen in paraplegic spinal cord injury patients. Ann Surg 1990; 212: 561-566.

13 Bar-On Z, Ohry A. The acute abdomen in spinal cord injury individuals. Paraplegia 1995; 33: 704-706.

14 Sugarman B, Brown D, Musher D. Fever and infection in spinal cord injury patients. JAMA 1982; 248: 66-70.

15 Everston GT. Gall bladder function in gallstone disease. Gastroenterol Clin North Am 1991; 20: 84-110.

16 Rotter KP, Larrain CG. Gallstones in spinal cord injury ( $\mathrm{SCl}$ ): a late medica complication? Spinal Cord 2003; 41: 105-108.

17 Karayalçın K. Asemptomatik kolelitiasis olgularında ne yapmalı. Türkiye Klinikleri J Surg Med Sci 2006; 2: 1-3.

18 Apstein MD, Dalecki-Chipperfield K. Spinal cord injury is a risk factor for gallstone disease. Gastroenterology 1987; 92: 966-968.

19 Moonka R, Stiens SA, Resnick WJ, McDonald JM, Eubank WB, Dominitz JA et al. The prevalence and natural history of gallstones in spinal cord injured patients. J Am Coll Surg 1999; 189: 274-281.

20 Tandon RK, Jain RK, Garg PK. Increased incidence of biliary sludge and normal gall bladder contractility in patients with high spinal cord injury. Gut 1997; 41 682-687

21 Ketover SR, Ansel HJ, Goldish G. Gallstones in chronic spinal cord injury: is impaired gallbladder emptying a risk factor? Arch Phys Med Rehabil 1996; 77: 1136-1138.

22 Xia CS, Han YQ, Yang XY, Hong GX. Spinal cord injury and cholelithiasis. Hepatobiliary Pancreat Dis Int 2004; 3: 595-598.

23 Ryu JK, Ryu KH, Kim KH. Clinical features of acute acalculous cholecystitis. J Clin Gastroenterol 2003; 36: 166-169.

24 Segal JL, Milne N. Gallbladder function in patients with spinal cord injury. AJR Am J Roentgenol 1991; 157: 412-413.

25 Fong YC, Hsu HC, Sun SS, Kao A, Lin CC, Lee CC. Impaired gallbladder function in spinal cord injury on quantitative Tc-99m DISIDA cholescintigraphy. Abdom Imaging 2003; 28: 87-91.

26 Yung JC, Groah SL. Crohn's disease in a patient with acute spinal cord injury: a case report of diagnostic challenges in the rehabilitation setting. Arch Phys Med Rehabil 2001; 82: 1274-1278. 